\title{
Correction to: Dubin-Johnson syndrome and intrahepatic cholestasis of pregnancy in a Sri Lankan family: a case report
}

Grace Angeline Malarnangai Kularatnam ${ }^{1 *}$, Hewa Dilanthi Warawitage ${ }^{1}$, Dinesha Maduri Vidanapathirana', Subashini Jayasena', Eresha Jasinge ${ }^{1}$, Ginige Nalika Nirmalene de Silva²,

Kirinda Liyana Arachchige Manoj Sanjeeva Liyanarachchi ${ }^{2}$, Pujitha Wickramasinghe ${ }^{3}$, Manjit Singh Devgun ${ }^{4}$, Veronique Barbu ${ }^{5}$ and Olivier Lascols ${ }^{5}$

\section{Correction to: BMC Res Notes (2017) 10:487 DOI 10.1186/s13104-017-2811-6}

Following publication of the original article [1], the authors requested the following corrections:

1. Author 2-given name should be Dilanthi and family name Warawitage

2. Author 6-given name should be Nalika and family name de Silva

The original article has been corrected.

\section{Author details}

${ }^{1}$ Department of Chemical Pathology, Lady Ridgeway Hospital for Children, Colombo, Sri Lanka. ${ }^{2}$ Lady Ridgeway Hospital for Children, Colombo, Sri Lanka. ${ }^{3}$ Department of Paediatrics, Faculty of Medicine, University of Colombo, Colombo, Sri Lanka. ${ }^{4}$ Clinical Laboratories, Department of Biochemistry, Wishaw General Hospital, Wishaw, Lanarkshire ML2 ODP, UK. ${ }^{5}$ Laboratoire Commun de Biologie et de Génétique Moléculaires, Hôpital Saint-Antoine, 184, rue du Faubourg Saint-Antoine, 75012 Paris, France.
The online version of the original article can be found under doi:10.1186/s13104-017-2811-6.

\section{Publisher's Note}

Springer Nature remains neutral with regard to jurisdictional claims in published maps and institutional affiliations.

Received: 26 September 2017 Accepted: 26 September 2017

Published online: 05 October 2017

\section{Reference}

1. Kularatnam GAM, Warawitage HD, Vidanapathirana DM, Jayasena S, Jasinge E, de Silva GNN, Liyanarachchi KLAMS, Wickramasinghe P, Devgun MS, Barbu V, Lascols O. Dubin-Johnson syndrome and intrahepatic cholestasis of pregnancy in a Sri Lankan family: a case report. BMC Res Notes. 2017;10:487. doi:10.1186/s13104-017-2811-6.

\footnotetext{
*Correspondence: ga_nangai@yahoo.com

1 Department of Chemical Pathology, Lady Ridgeway Hospital

for Children, Colombo, Sri Lanka

Full list of author information is available at the end of the article
} 